\title{
Oral therapies in digestive oncology (Review)
}

\author{
CAROLINE PRIEUX-KLOTZ ${ }^{1}$, SOLENE DERMINE ${ }^{2,3}$, LOLA-JADE PALMIERI ${ }^{2}$, JULIE LAVOLE ${ }^{2}$, \\ STANISLAS CHAUSSADE ${ }^{2,3}$, CATHERINE BREZAULT ${ }^{2}$ and ROMAIN CORIAT ${ }^{2,3}$
}

\author{
${ }^{1}$ Department of Hepatology and Gastroenterology, Percy Military Hospital, 92140 Clamart; ${ }^{2}$ Department of Gastroenterology, \\ Cochin Teaching Hospital, 75014 Paris; ${ }^{3}$ Paris Descartes University, Sorbonne Paris, Faculty of Medicine, 75006 Paris, France
}

Received May 27, 2019; Accepted December 13, 2019

DOI: $10.3892 /$ or.2020.7555

\begin{abstract}
Targeted therapy and oral chemotherapy indications are increasing in the realm of digestive oncology. Oral intake of cancer agents is sometimes compulsory (no i.v. equivalent) or is preferred by the patient or the physician. Although oral chemotherapy facilitates the treatment of oncology patients, the treatment diversity, risk of pharmaceutical interactions and monitoring of side effects are potentially challenging and need to be fully acknowledged by the physician. We offer here a literature review of the indications, doses, side effects and monitoring of every oral therapy indicated in Digestive Oncology. We suggest a prescription algorithm including therapeutic education by the physician or a trained nurse, and pharmaceutical counseling.
\end{abstract}

\section{Contents}

1. Introduction

2. Oral chemotherapy

3. Targeted therapies

4. Practical aspects

5. Conclusions

\section{Introduction}

The indications for the use of oral therapies in the field of digestive oncology are increasing. Whether oral chemotherapy or targeted therapies, their use is favored by patients. Adherence to treatment is directly linked with the patient's understanding, the ability to remember the information provided by the physician, treatment length and psychological distress (1). A good coordination between oncologists, general practitioners,

Correspondence to: Dr Caroline Prieux-Klotz, Department of Hepatology and Gastroenterology, Percy Military Hospital, 101 Henri Barbusse Avenue, 92140 Clamart, France

E-mail: prieuxcaroline@gmail.com

Key words: oral therapy, cancer, digestive oncology, pharmaceutical counselling, therapeutic education pharmacists and nurses is essential, information about drug monitoring and management of the side effects has to be widely distributed. Drug and food interactions have to be known by the oncologist. We herein propose an updated review of the literature about oral therapies in digestive oncology and a short reminder of how to use them and to manage their side effects.

\section{Oral chemotherapy}

Capecitabine. Capecitabine is an antimetabolite, an oral prodrug of 5-fluorouracil (5-FU), which is metabolized to 5'-deoxy-5-fluorocytidine, 5'-deoxy-5-fluouridine and 5 fluorouracil by cytidine deaminase and thymidine phosphorylase. Capecitabine is a uracil-based nucleic acid analog that inhibits thymidylate synthase, resulting in inhibition of DNA synthesis and RNA damage. It has been shown that 5-FU concentrations after capecitabine intake are higher in colorectal tumors than levels in healthy tissue, due to cytidine deaminase and thymidine phosphorylase concentrations in these tumors (2).

A systematic screening for dihydropyrimidine dehydrogenase (DPD) deficiency is recommended before any administration of 5-FU-based chemotherapy (3).

Capecitabine is administered orally, twice a day, in a divided dose $12 \mathrm{~h}$ apart, $30 \mathrm{~min}$ after a meal. Tablets come in 2 doses; 150 and $500 \mathrm{mg}$.

In a neoadjuvant setting, capecitabine is indicated in association with radiotherapy. The standard neoadjuvant CAP50 regimen is recommended in rectal T3-4M0 cancer (4), with a dose of concomitant capecitabine $800 \mathrm{mg} / \mathrm{m}^{2}$ twice daily, 5 days per week.

In adjuvant situations, capecitabine is applied in monotherapy with a $1250 \mathrm{mg} / \mathrm{m}^{2}$ dose twice daily, 14 days $/ 21$ after complete resection of a cholangiocarcinoma, as shown in the recent BILCAP study (5). Capecitabine monotherapy can be discussed in adjuvant therapy for stage II colorectal cancer (CRC), or in stage III after 70 years of age (6). In association with oxaliplatin, capecitabine is administered at the dose of $1,000 \mathrm{mg} / \mathrm{m}^{2}$ twice daily, 14 days $/ 21$ in adjuvant for stage II/III $\mathrm{CRC}$, for 3 or 6 months, as shown in the IDEA study (7). In association with gemcitabine after surgery for pancreatic adenocarcinoma, capecitabine is administered at the dose of $1,660 \mathrm{mg} / \mathrm{m}^{2}$ daily, 21 days $/ 28$ (ESPAC-4 study) (8).

In metastatic situations, capecitabine can replace intravenous 5-FU in monotherapy, doublet, or triplet with targeted therapy (9). Capecitabine is preferentially used in maintenance 
therapy in association with bevacizumab in CRC (10). In pancreatic neuroendocrine tumors (NETs), administration of capecitabine at a dosage of $750 \mathrm{mg} / \mathrm{m}^{2}$ twice daily from day 1 to 14 and temozolomide at $200 \mathrm{mg} / \mathrm{m}^{2}$ once daily from day 10 to 14 every 28 days was found to be associated with durable response rate (11).

Oncologists and pharmacists have to be aware of drug interactions, and the most common is in regards to warfarin, which is prohibited during capecitabine treatment (12). It has also been shown that proton pump inhibitors (PPIs) negatively affect capecitabine efficacy, by modifying gastric $\mathrm{pH}$ leading to altered absorption (13). The use of PPIs must be withdrawn when possible.

Toxicity associated with capecitabine is described in nearly $80 \%$ of patients (14), and up to $40 \%$ grade III. Nausea and vomiting from 3 to $35 \%$ is observed depending on the studies $(5,6,9,15,16)$, mucositis is observed in 2 to $22 \%$ of cases, diarrhea up to $30 \%$, hand and foot syndrome, $17 \%$ and hematologic toxicity less than $10 \%$. Cardiac toxicity is described at a range of 3 to $6 \%$, and its incidence increases with the presence of underlying cardiopathy. The incidence of toxicity and grade depends on the dose, combination therapy and the DPD status.

Systematic education for hand and foot syndrome management, mucositis management and treatment for digestive side effects must be provided at initial capecitabine prescription.

TAS 102. TAS-102 is an orally administered combination of a thymidine-based nucleic acid analogue, trifluridine and a thymidine phosphorylase inhibitor, tipiracil. Tipiracil improves the bioavailability of trifluridine by inhibiting its catabolism by thymidine phosphorylase.

The only indication validated to this day was for refractory metastatic CRC after oxaliplatin and 5 FU-based chemotherapy and irinotecan and 5 FU-based chemotherapy (targeted therapies included). TAS-102 was administered at a dose of $35 \mathrm{mg} / \mathrm{m}^{2}$ twice a day, 5 days a week, with 2 days of rest for 2 weeks followed by a 14-day rest period. Overall survival was 7.1 months (vs. 5.3 months in the placebo group; $\mathrm{P}<0.001)(17)$.

Toxicity was found to be mainly hematologic, with $38 \%$ of $\geq$ grade III neutropenia, with $4 \%$ febrile neutropenia. Mild nausea (grade I-II) and vomiting have been described in 48 and $28 \%$ of cases, respectively (17).

Temozolomide. Temozolomide is an oral alkylating agent indicated for the treatment of neuroendocrine pancreatic carcinoma, in association with capecitabine. Temozolomide is an alkylating agent prodrug, delivering a methyl group to purine bases of DNA. DNA alkylation induces cell cycle arrest at $\mathrm{G} 2 / \mathrm{M}$ phase of mitosis eventually leading to apoptosis (18).

The indication for temozolomide in the treatment of pancreatic NETs was studied by Strosberg et al (11). The regimen consisted of oral capecitabine at $750 \mathrm{mg} / \mathrm{m}^{2}$ twice a day for 14 days (days 1-14) and oral temozolomide at $200 \mathrm{mg} / \mathrm{m}^{2}$ once a day at bedtime for 5 days (days 10-14) every 28 days. The dose was adapted in the case of renal insufficiency. Median progression-free survival was 18 months.

The first prospective randomized study was presented this year (ASCO) (19) comparing temozolomide alone vs. temozolomide and capecitabine in patients with advanced pancreatic neuroendocrine carcinoma, in progression after targeted therapy or somatostatin analogues. Progression-free survival was 22.7 months in the temozolomide+capecitabine group vs. 14.4 months in the temozolomide group $(\mathrm{P}=0.023)$. Overall survival was not reached in the bi-chemotherapy group, vs. 38 months in the temozolomide group $(\mathrm{P}=0.012)$. Predictive value of MGMT status for temozolomide response was studied in pancreatic NETs. Combination therapy induced more side effects $(44 \%)$, with $13 \%$ grade III or more neutropenia. Digestive side effects were present in $8 \%$ of cases.

\section{Targeted therapies}

Sorafenib. Sorafenib is an oral multikinase inhibitor of the vascular endothelial growth factor receptor (VEGFR), the platelet-derived growth factor receptor (PDGFR) and Raf kinase. Sorafenib inhibits tumor cell proliferation and angiogenesis (20).

Sorafenib is indicated in the first-line treatment of advanced HCC (21) at the dose of $400 \mathrm{mg}$ twice daily. It is recommended to take sorafenib as far away as possible from meal-times or with a low-fat diet for better absorption. No adaptation is necessary in case of renal dysfunction. In case of cirrhosis, sorafenib is indicated in the case of Child A score. In a study by Llovet et al (21) enrolling 602 patients with advanced $\mathrm{HCC}$ without previous systemic treatment, the median overall survival of the patients was 10.7 months in the sorafenib group vs. 7.9 months in the placebo group $(\mathrm{P}<0.001)$. Toxicity described in the sorafenib group included diarrhea $(55 \%)$, weight loss $(30.9 \%)$, anorexia $(28.6 \%)$, hand and foot syndrome $(21.2 \%)$, vomiting $(14.8 \%)$ and alopecia $(14.1 \%)$. A treatment discontinuation was necessary in $31.6 \%$ of the patients due to these side effects.

Lenvatinib. Lenvatinib is a multikinase inhibitor, targeting VEGF receptors 1-3, fibroblast growth factor (FGF) receptors $1-4$, PDGF receptor $\alpha$, RET and KIT. Lenvatinib is indicated in $\tau \eta \varepsilon$ first-line treatment for unresectable or metastatic hepatocellular carcinoma (22). The recommended dose is $12 \mathrm{mg}$ /day for body weight $\geq 60 \mathrm{~kg}$ or $8 \mathrm{mg} /$ day for $<60 \mathrm{~kg}$. Kudo et al (22) enrolled 1,492 unresectable hepatocellular carcinoma patients randomly assigned to lenvatinib or sorafenib as first-line treatment. The median survival time for lenvatinib was 13.6 months (95\% CI, 12.1-14.9), not inferior to sorafenib [(12.3 months, 10.4-13.9), HR 0.93, 95\% CI, 0.79-1.06]. The most common any-grade adverse events for lenvatinib were fatigue (30\%, grade $\geq 3: 4 \%$ ), hypertension ( $42 \%$, grade $\geq 3: 23 \%$ ), diarrhea (39\%) grade $\geq 3: 4 \%$ ), anorexia (34\%, grade $\geq 3: 5 \%$ ), decreased weight $(31 \%$, grade $\geq 3: 8 \%)$. A similar tolerance profile was observed in an elderly population (23).

Regorafenib. Regorafenib is an oral multikinase inhibitor which targets angiogenic, stromal and oncogenic tyrosine kinase receptors. Inhibition of angiogenesis is accomplished by inhibition of VEGF, fibroblast growth factor (FGF) and PDGF receptors. Inhibition of metastatic invasion was found to be due to the inhibition of VEGFR2 and VEGFR3. Oncogenic inhibition was found to be induced by inhibition of the MAP kinase pathway. Regorafenib was administered at a dose of $160 \mathrm{mg}$ daily, in the morning $(4 \times 40 \mathrm{mg})$ associated with a low-fat breakfast, during 3 weeks over a 4-week cycle (24). 


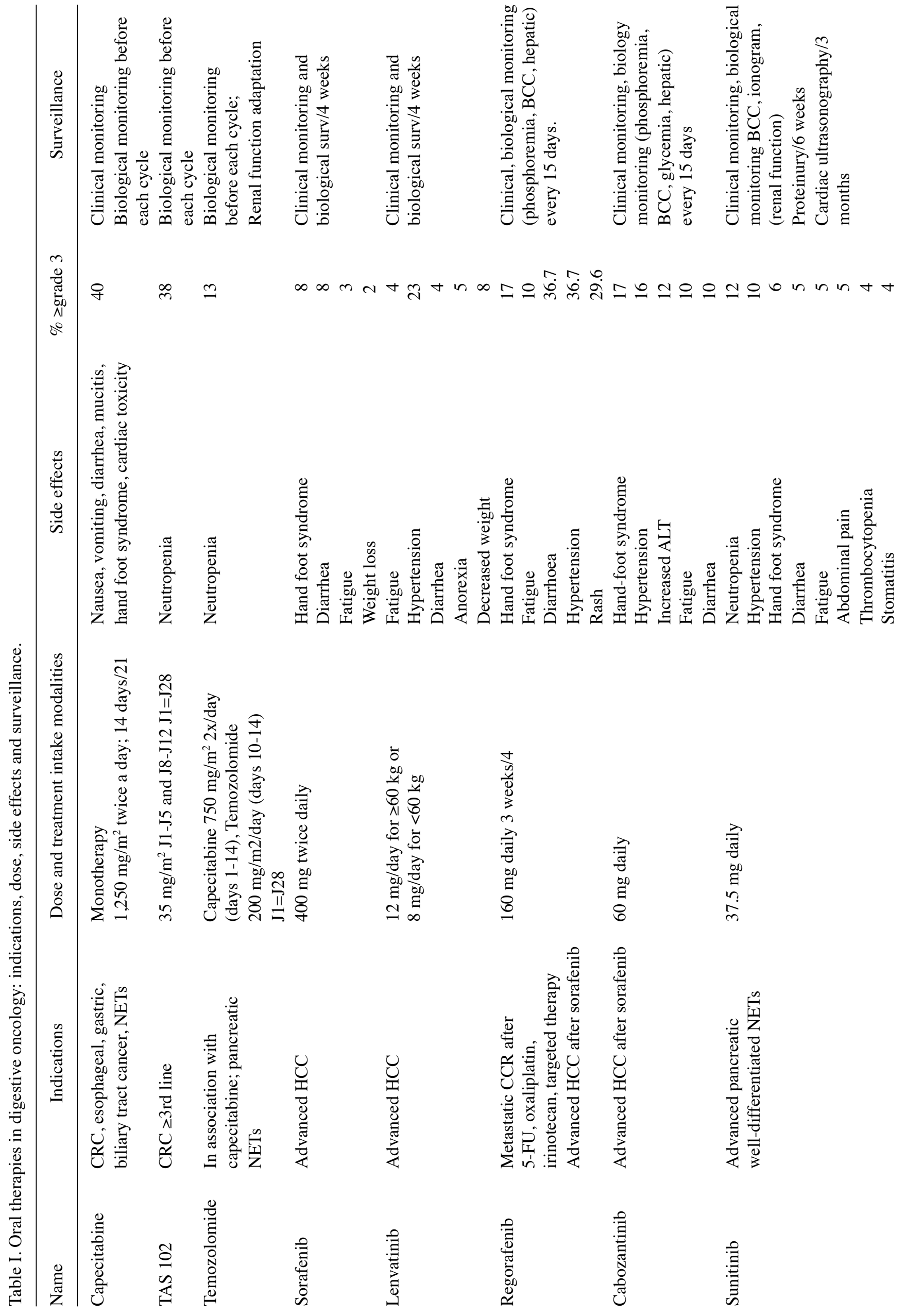




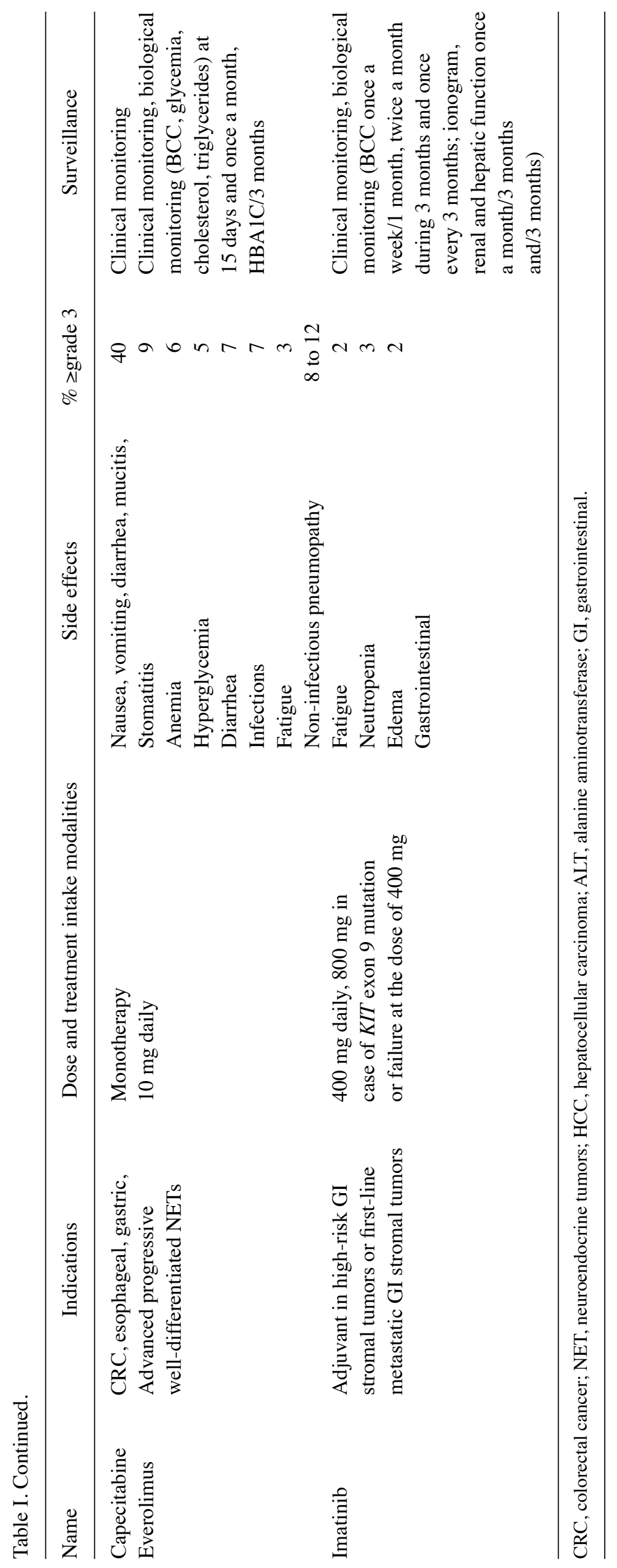




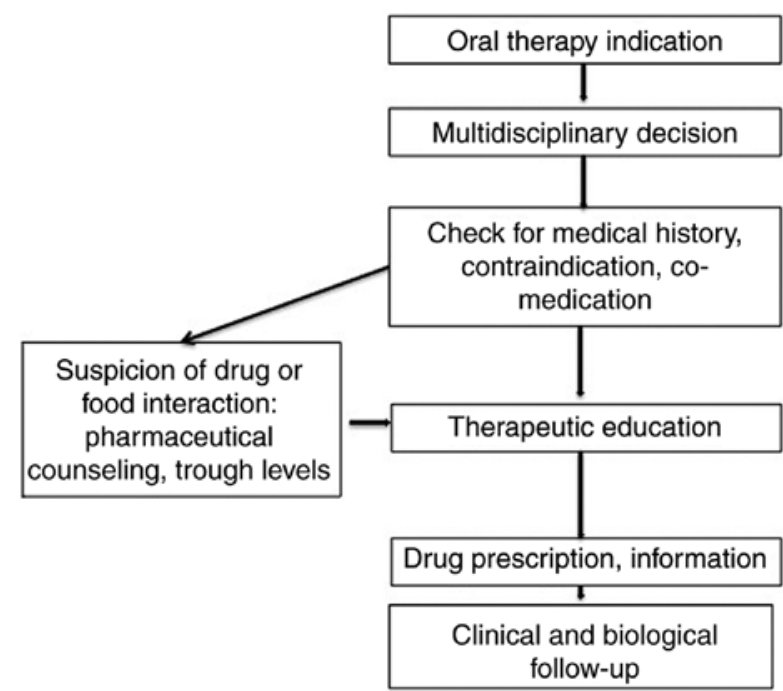

Figure 1. Proposition of an algorithm for the initiation of oral therapy in digestive oncology.

Regorafenib is indicated for patients with metastatic CRC previously treated with fluoropyrimidine-based chemotherapy, anti-VEGF or anti-EGFR therapy. The CORRECT study (25) included 760 metastatic CRC PS 0 or 1 patients after failure of fluoropyrimidine, oxaliplatin, irinotecan, bevacizumab and anti-EGFR therapy of RAS wild-type tumors. They received either placebo or regorafenib at $160 \mathrm{mg}$ per day. The median overall survival was 6.4 months in the regorafenib group vs. 5 months in the placebo group (HR=0.77, 95\% CI, 0.64-0.94).

A multicentric randomized phase II study was carried out and enrolled 123 metastatic CRC patients treated with regorafenib; randomized between a dose-escalation strategy (starting dose $80 \mathrm{mg} /$ day taken orally with weekly escalation, per $40 \mathrm{mg}$ increment, to $160 \mathrm{mg} /$ day regorafenib) vs. a standard dose strategy (160 mg/day) (26). A comparable anti-tumoral activity was observed, with lower incidence of adverse events in the 'dose escalation strategy' group. This strategy is due to be implemented in clinical practice.

Regorafenib is also indicated in advanced HCC after sorafenib treatment. The RESORCE study (27) randomized 573 HCC (Child A) patients between best supportive care or regorafenib $160 \mathrm{mg}$ daily 3 weeks/4. Patients had to have tolerated sorafenib at least $400 \mathrm{mg} / \mathrm{day}$ for at least 20 of the last 28 days of treatment. Regorafenib improved overall survival: 10.6 vs. 7.8 months $(\mathrm{HR}=0.63,95 \%$ CI $0.50-0.79)$.

Regorafenib is also indicated in metastatic or unresectable gastrointestinal (GI) stromal tumors after intolerance or failure of imatinib and sunitinib (28), with a dose of $160 \mathrm{mg}$ per day 3 weeks/4. The median progression-free survival vs. placebo was 4.8 vs. 0.9 months $(\mathrm{P}<0.001)$.

In the CORRECT study (25) the most common adverse events of grade III or higher were hand-foot syndrome (18\%), asthenia (10\%), diarrhea (36.7\%), hypertension (36.7\%), rash or desquamation (29.6\%). In the RESORCE study (27), at least grade III or higher adverse events consisted of hypertension $(15 \%)$, hand-foot syndrome $(13 \%)$, asthenia $(9 \%)$ and diarrhea $(3 \%)$.
Biological monitoring during regorafenib treatment includes phosphoremia, blood cell count (cytopenia) and hepatic biology. Regorafenib is forbidden in case of recent ( $<6$ months) arterial thrombosis.

Cabozantinib. Cabozantinib is a tyrosine kinase inhibitor which targets VEGF1, VEGF2, VEGF3, hepatocyte growth factor receptor (MET) and $\mathrm{AXL}$ receptor tyrosine kinase (AXL), which are implicated in the progression of HCC and the development of resistance to sorafenib. Inhibition of VEGFR and c-MET decreases resistance of VEGFR inhibitor via c-Met axis (29).

Cabozantinib is indicated for the treatment of non-resectable HCC after progression with sorafenib. A randomized double-blind phase III trial recruited 707 HCC patients after progression with sorafenib. The patients received either cabozantinib $60 \mathrm{mg}$ once daily or placebo (30). The median overall survival was longer with cabozantinib, 10.2 months vs. 8 months (HR for death 0.76, 95\% CI, 0.63-0.92, $\mathrm{P}=0.005$ ). Principal grade III or higher adverse events included palmar-plantar-erythrodysesthesia (17\%), arterial hypertension $(16 \%)$, increased alanine aminotransferase (ALT) (12\%), fatigue (10\%) and diarrhea (10\%).

Biological monitoring for this agent includes testing for blood cell count, hepatic biology, TSH, glycemia and electrolytes.

Sunitinib. Sunitinib is a multi-targeted tyrosine kinase inhibitor indicated for the treatment of advanced well-differentiated pancreatic neuroendocrine carcinoma. Sunitinib has been identified as an inhibitor of VEGFR1, VEGFR2, VEGFR3, KIT proto-oncogene, receptor tyrosine kinase (KIT), proto-oncogene tyrosine-protein kinase receptor Ret (RET) and PDGFRA. The recommended dose is $37.5 \mathrm{mg}$ daily continuously (31).

A phase III randomized trial of sunitinib treatment vs. a placebo included 171 patients who had progressive pancreatic well-differentiated neuroendocrine carcinoma (32). The median progression-free survival was 11.4 months in the sunitinib group vs. 5.5 months for the placebo group (HR for progression or death 0.42 , IC 95\% 0.26-0.66, $\mathrm{P}<0.001)$. The HR for death was 0.41 (IC $95 \% 0.19$ to $0.89, \mathrm{P}=0.02$ ).

Sunitinib is also indicated for the treatment of metastatic or unresectable GI stromal tumors, after imatinib resistance or intolerance $(32,33)$. The recommended dose is $50 \mathrm{mg}$ per day for 4 weeks $/ 6$, but a dose of $37.5 \mathrm{mg}$ per day continuously showed an acceptable toxicity profile and similar efficiency in a non-randomized phase II study (33).

Grade III or greater adverse events included neutropenia (12\%), hypertension (10\%), palmar-plantar-erythrodysesthesia $(6 \%)$, diarrhea $(5 \%)$, fatigue $(5 \%)$, abdominal pain $(5 \%)$, stomatitis $(4 \%)$ and thrombocytopenia $(4 \%)(32,33)$.

A transthoracic ultrasonography is recommended before treatment initiation and every 3 months, due to a possible decreased left ventricular ejection fraction (LVEF). Urine analysis (protein) is recommended every 6 weeks. Co-medication with P450 cytochrome treatments must be monitored (34).

Everolimus. Everolimus is a selective mammalian target of rapamycin (mTOR) inhibitor. Everolimus inhibits tumor cell 


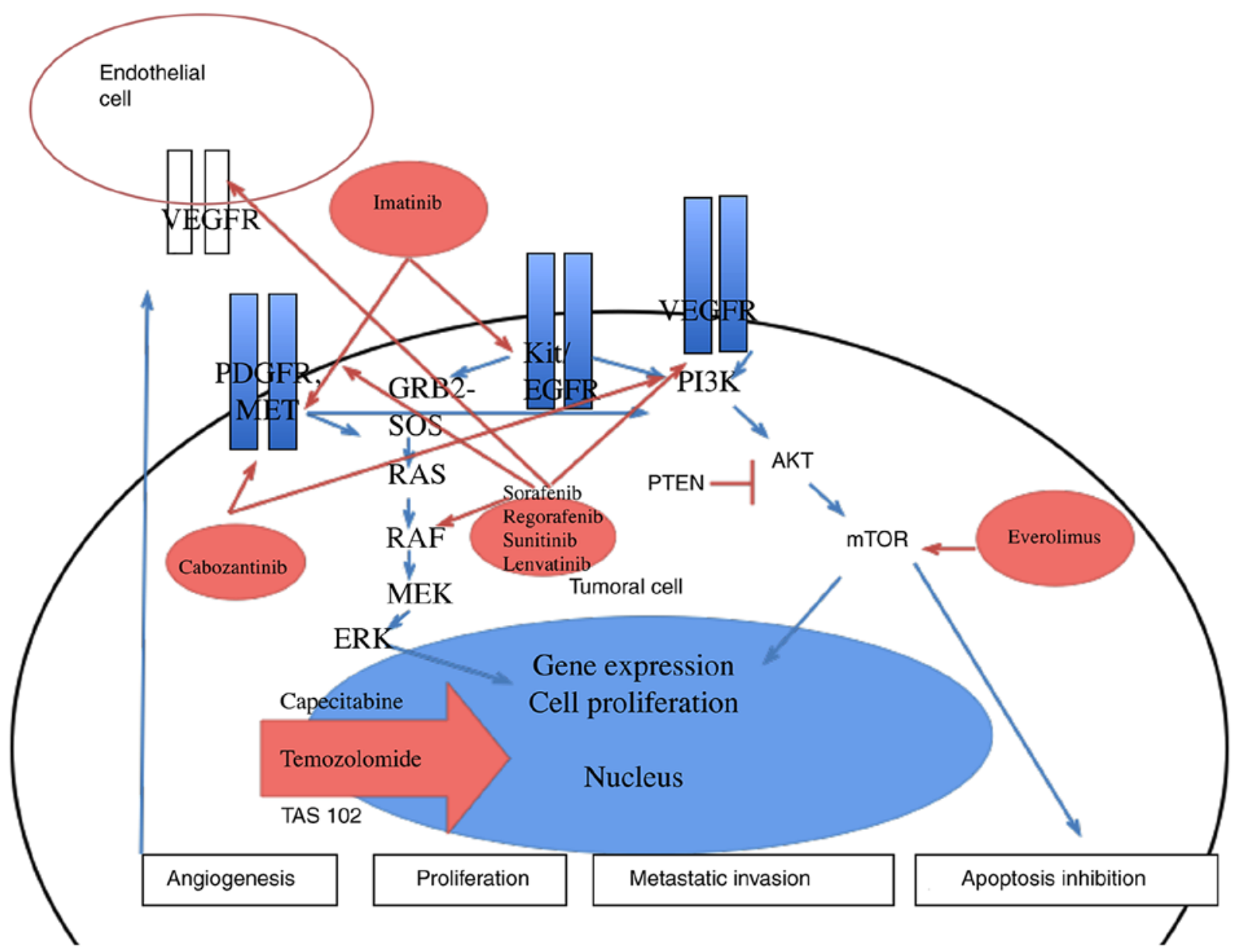

Figure 2. Simplified pathway of tumor proliferation and the mechanisms of action of oral therapeutic agents for digestive oncology. VEGFR, vascular endothelial growth factor receptor; PDGFR, platelet-derived growth factor receptor; MET, hepatocyte growth factor receptor; GRB2, growth factor receptor bound protein 2; SOS, SOS Ras/Rac guanine nucleotide exchange factor; PTEN, phosphatase and tensin homolog; PI3K, phosphoinositide 3-kinase; mTOR, mammalian target of rapamycin.

growth as well as that of endothelial cells and fibroblasts. Everolimus is indicated for the treatment of advanced and progressive well-differentiated digestive neuroendocrine tumors (35-37). The dose recommended is $10 \mathrm{mg}$ per day continuously.

In the RADIANT-3 study (37), 410 patients with advanced low-grade or intermediate-grade pancreatic progressive neuroendocrine tumors were randomized between an everolimus $10 \mathrm{mg} / \mathrm{day}$ group and a placebo group. The median progression-free survival was 11 months in the everolimus group vs. 4.6 months in the placebo group $(\mathrm{P}<0.001)$.

In the RADIANT-4 study (36), 302 patients with advanced progressive well-differentiated neuroendocrine tumors of pulmonary or gastrointestinal origin were enrolled, and randomized between an everolimus $10 \mathrm{mg}$ per day group and a placebo group. The median progression-free survival was 11 months in the everolimus group vs. 3.9 months in the placebo group $(\mathrm{P}<0.00001)$ and no significance in overall survival.

Grade 3 or 4 events with everolimus included anemia (6\%), hyperglycemia (5\%), stomatitis (9\%), diarrhea (7\%), infections (7\%) and fatigue (3\%). A non-infectious pneumopathy was observed in $12 \%$ of cases; therefore, a systematic clinical investigation for dyspnea, auscultation and pulmonary evaluation on TDM is recommended (36,37). A systematic follow-up of metabolic disorders induced by everolimus should be performed at day 15 , and then once a month (38).

Additionally there is a high risk of toxicity linked with the association of inhibitors of p 450 cytochrome, which could lead to a dose reduction and should justify a close watch (39).

Imatinib mesylate. Imatinib is a tyrosine kinase inhibitor targeting BCR-ABL tyrosine kinase and stem cell factor receptor, encoded by the proto-oncogene c-Kit, and PDGFR. Competitive inhibition at the ATP-binding site of BCR-ABL tyrosine kinase leads to inhibition of tyrosine phosphorylation of proteins involved in BCR-ABL signal transduction. Imatinib also inhibits the receptor PDGFR and KIT (40). The recommended dose is 400 to $800 \mathrm{mg}$ once daily during a meal.

Imatinib is indicated as an adjuvant therapy for high risk stromal tumors or in cases of metastatic stromal tumors.

In an adjuvant situation, a phase III randomized trial (41) included patients who underwent surgery for a gastrointestinal stromal tumor of at least $3 \mathrm{~cm}$, and who were randomized between a placebo $(\mathrm{N}=354)$ and imatinib $400 \mathrm{mg}$ per day $(\mathrm{N}=359)$ daily group, for 1 year after tumor resection. At 1 year, imatinib significantly improved the recurrence-free survival of the imatinib group compared with the placebo group [HR=0.35 (0.22-0.53), $\mathrm{P}<0.0001]$. In the imatinib group, 
grade III or IV adverse events occurred in $30.9 \%$ of the cases. Grade III edema was noted in $2 \%$, grade III or IV neutropenia in $3 \%$ and grade III or IV fatigue in $2 \%$ of the cases.

A secondary analysis concerning the function of tumor genotype was performed (42), confirming that KIT exon 11 mutation was associated with the significantly improved prognosis in the imatinib treatment, contrary to exon 9 mutation or wild-type genotype. Imatinib did not benefit patients with a PDGFRA mutation type D 842V of exon 18.

Joensuu et al (43) assessed adjuvant therapy with imatinib for 1 to 3 years in 400 patients with operable GI stromal tumors with a high risk of recurrence (size, mitosis, tumoral breach). Recurrence-free survival was $66 \%$ in the 3 -year treatment group vs. $48 \%$ in the 1 -year treatment group $(\mathrm{P}<0.0001)$. After 5 years, the overall survival was 93 vs. $87 \%(\mathrm{P}=0.032)$, in favor of the 3-year treatment. A 3-year treatment was also recommended in adjuvant therapy for high-recurrence risk stromal tumors.

Imatinib is recommended for cases of metastatic GI stromal tumors $(44,45)$. In cases with KIT exon 9 mutation, a higher dose of $800 \mathrm{mg}$ per day is recommended, as well as in the event of progression at the dose of $400 \mathrm{mg}$ per day (46).

Table I provides a summary of drug indications, dose, principal side effects and monitoring.

\section{Practical aspects}

Initiating oral therapy. Similar to every treatment in oncology, the prescription must follow a multidisciplinary decision. Before initiating oral therapy, medical history of the patient must be known by the clinician, as well as co-medications. Therapeutic education for the treatment's modalities and side effects is essential, completed by the physician or specially trained oncology nurses (47). Patients therefore tend to handle side effects and critical situations better.

Pharmaceutical counseling is suggested (48), to alert the patient to the importance of compliance with therapy, as well as for interactions with concomitant medication and food. Treatment trough levels should be assessed in the case of a suspicion of pharmaceutical interactions, primary treatment failure, before dose optimization (Fig. 1).

Fig. 1 illustrates the proposition of a decisional pathway for initiating oral therapy in digestive oncology. A multidisciplinary decision must lead to the initial prescription, with an assessment of the patient's medical history co-medication or contraindications. Pharmaceutical counseling can be useful in these cases. Therapeutic education and clinical close follow-up must be organized.

Fig. 2 summarizes the oral therapies used in digestive oncology, the simplified pathway of tumoral proliferation and the mechanisms of action of the various oral therapies. As cytotoxic therapies are mainly mitosis inhibitors, targeted therapies such as multikinase inhibitors act on pathways related to cell proliferation, angiogenesis, and metastatic invasion.

Selection of personalized therapy. The therapeutic choice is sometimes difficult, as in some clinical situations there are no head-to-head clinical trials. As an example, in the treatment of refractory metastatic CRC, regorafenib or TAS 102 are both approved (17,25). Moreover, patient preferences, medical history and tolerance to previous medication must be taken into account.

A retrospective study of 550 Japanese patients (49) observed no difference in overall survival between patients receiving regorafenib or TAS 102 . In a subgroup analysis, a significant interaction with age was observed; regorafenib treatment showed favorable survival in patients aged $<65$ years (HR 1.29, 95\% CI 0.98-1.69); and TAS 102 showed favorable survival in patients aged $>65$ years (HR $0.78 ; 95 \%$ CI 0.59-1.03). Tolerance of side effects and adherence to treatment must be taken into account in interpretation of such retrospective results.

An observational study enrolled 469 patients treated with TAS 102 and 311 treated with regorafenib for metastatic CRC, aiming to describe real-world adherence to treatment (50). Patients treated with TAS 102 had higher compliance to treatment, better persistence and lower risk of discontinuation than patients treated with regorafenib ( $\mathrm{HR} 0.76, \mathrm{P}=0.006)$.

A dose optimization (ReDOS study) (26) with regorafenib could be a way to strengthen treatment continuation and lower incidence of adverse events.

\section{Main adverse events management}

Nausea and vomiting. Up to $80 \%$ of patients receiving chemotherapy experience nausea or vomiting. Preventive treatment is important and is currently used in i.v. chemotherapy; depending on the emetogenical potential of agents (high emetic risk, $>90 \%$; moderate risk, 30-90\%; low risk, 10-30\%; minimal risk, $<10 \%$ ). The ESMO guidelines recently classified oral therapies by their emetic potential, based upon a full course of therapy and not a single dose (51). For example, imatinib and temozolomide were classified as moderately emetogenic. Capecitabine, everolimus, regorafenib and sunitinib were classified as having low emetic risk, and sorafenib as having minimal risk. For low or minimal risk there is no recommendation for an anti-emetic prophylaxis (51). Metoclopramide or a setron (granisetron, odansetron) can be prescribed in the case of delayed nausea. In the case of refractory nausea or vomiting, dexamethasone and olanzapine (10 $\mathrm{mg}$ orally for 3 days) is available (51).

Diarrhea. Treatment-related diarrhea is described as a frequent side effect with capecitabine and tyrosine kinase inhibitors. Its severity is assessed by the number of bowel movements, a need of hospitalization and the effects on activities of self-care. In mild-to-moderate diarrhea, a simple treatment with oral hydration, dietary modifications (fibers decreased) and loperamide (4 mg to start and then $2 \mathrm{mg}$ after each loose stool) is recommended. In the case of severe diarrhea hospitalization can be necessary for an i.v. hydroelectrolytic supplementation, stool bacteriological examination, discussing CT scan or endoscopic explorations. Somatostatin and budesonide have shown to be effective for refractory i.v. chemotherapy-induced diarrhea (52).

Hand and foot syndrome. Severe hand and foot syndrome, often occurring in patients treated with multikinase inhibitors or capecitabine can be painful and interfere with normal daily activities. Supportive measures must be initiated as soon as the symptoms appear. To relieve inflammation, the application of cold packs, the use of moisturizing creams, topical preparations containing vasoconstrictor (eg. phenylephrine), astringents, anesthetics or dermocorticoids can be used (53). 
In hyperkeratosis, keratolytic agents such as urea-based cream are useful. Hydrocolloid or alginate dressing may be used to protect pressure points and aid healing. Treatment discontinuation should be discussed in case of toxicity $\geq$ grade 2 .

Mucositis. Oral mucositis can be painful and affect nutritional intake, oral treatment intake and quality of life. Oral decontamination by brushing with a soft toothbrush, flossing and the use of sodium bicarbonate rinses are the first step in treatment (54). Pain control with the use of viscous lidocaine, which can be mixed with equal volumes of soothing covering agents such as kaopectate may provide short-term relief. Treatment of an associated candidosis infection with fluconazole can be helpful. Nutritional support and treatment discontinuation should be discussed in the case of severe mucositis.

\section{Conclusions}

Various oral therapies can be prescribed in digestive oncology. Classic chemotherapies such as capecitabine, TAS 102 and temozolomide are often well known by physicians, from their prescription modalities to the monitoring of the side effects. However, targeted therapies and the risk of drug or food interactions and their specific side effects are challenging. In neuroendocrine tumors as well as in stromal tumors, drug exposure spreads over an extended period of time. Therefore, dealing with side effects and drug interactions is a common occurrence and digestive oncologists should be able to know how to handle them. A multidisciplinary association with the pharmacist and a trained nurse should be developed.

\section{Acknowledgements}

Not applicable.

\section{Funding}

No funding was received.

\section{Availability of data and materials}

Not applicable.

\section{Authors' contributions}

CPK was involved in the conception and design of the research, drafting and revision of the review. SD, LJP and JL were involved in acquisition and analysis of the work, and drafting of the manuscript. SC, CB and RC carried out the interpretation of the data for the review and revision of the manuscript. All authors contributed to the literature review and gathering of the data and information. All authors read and approved the final manuscript and agree to be accountable for all aspects of the research in ensuring that the accuracy or integrity of any part of the work are appropriately investigated and resolved.

\section{Ethics approval and consent to participate}

This article does not contain any studies with human participants or animals performed by any of the authors.

\section{Patient consent for publication}

Not applicable.

\section{Competing interests}

CPK, SD, LJP, JL, SC and CB declare no competing interest. $\mathrm{RC}$ acts as consultant or speaker for Bayer, Amgen, Novartis, Servier, Ipsen, Keocyt, AAA, Roche, and Merck.

\section{References}

1. Bassan F, Peter F, Houbre B, Brennstuhl MJ, Costantini M, Speyer E and Tarquinio C: Adherence to oral antineoplastic agents by cancer patients: Definition and literature review. Eur J Cancer Care (Engl) 23: 22-35, 2014.

2. Schüller J, Cassidy J, Dumont E, Roos B, Durston S, Banken L, Utoh M, Mori K, Weidekamm E and Reigner B: Preferential activation of capecitabine in tumor following oral administration to colorectal cancer patients. Cancer Chemother Pharmacol 45: 291-297, 2000.

3. Loriot MA, Ciccolini J, Thomas F, Barin-Le-Guellec C, Royer B Milano G, Picard N, Becquemont L, Verstuyft C, Narjoz C, et al: Dihydropyrimidine déhydrogenase (DPD) deficiency screening and securing of fluoropyrimidine-based chemotherapies: Update and recommendations of the French GPCO-Unicancer and RNPGx networks. Bull Cancer 105: 397-407, 2018 (In French).

4. Gérard JP, Azria D, Gourgou-Bourgade S, Martel-Laffay I, Hennequin C, Etienne PL, Vendrely V, François E, de La Roche G, Bouché O, et al: Comparison of two neoadjuvant chemoradiotherapy regimens for locally advanced rectal cancer: Results of the phase III trial ACCORD 12/0405-Prodige 2. J Clin Oncol 28: 1638-1644, 2010.

5. Primrose JN, Fox RP, Palmer DH, Malik HZ, Prasad R, Mirza D, Anthony A, Corrie P, Falk S, Finch-Jones M, et al: Capecitabine compared with observation in resected biliary tract cancer (BILCAP): A randomised, controlled, multicentre, phase 3 study. Lancet Oncol 20: 663-673, 2019.

6. Twelves C, Wong A, Nowacki MP, Abt M, Burris H III, Carrato A, Cassidy J, Cervantes A, Fagerberg J, Georgoulias V, et al: Capecitabine as adjuvant treatment for stage III colon cancer. N Engl J Med 352: 2696-2704, 2005.

7. Grothey A, Sobrero A, Meyerhardt JA, Yoshino T, Paul J, Taieb J, Souglakos I, Kerr R, Labianca R, Shields AF, et al: Prospective pooled analysis of six phase III trials investigating duration of adjuvant (adjuv) oxaliplatin-based therapy (3 vs. 6 months) for patients (pts) with stage III colon cancer (CC): Updated results of IDEA (International Duration Evaluation of Adjuvant Chemotherapy). Ann Oncol 28 (Suppl 5): v605-v649, 2017.

8. Neoptolemos JP, Palmer DH, Ghaneh P, Psarelli EE, Valle JW, Halloran CM, Faluyi O, O'Reilly DA, Cunningham D, Wadsley J, et al: Comparison of adjuvant gemcitabine and capecitabine with gemcitabine monotherapy in patients with resected pancreatic cancer (ESPAC-4): A multicentre, open-label, randomised, phase 3 trial. Lancet 389: 1011-1024, 2017.

9. Cunningham D, Starling N, Rao S, Iveson T, Nicolson M, Coxon F, Middleton G, Daniel F, Oates J and Norman AR; Upper Gastrointestinal Clinical Studies Group of the National Cancer Research Institute of the United Kingdom: Capecitabine and oxaliplatin for advanced esophagogastric cancer. N Engl J Med 358: 36-46, 2008.

10. Simkens LH, van Tinteren H, May A, ten Tije AJ, Creemers GJ, Loosveld OJ, de Jongh FE, Erdkamp FL, Erjavec Z, van der Torren AM, et al: Maintenance treatment with capecitabine and bevacizumab in metastatic colorectal cancer (CAIRO3): A phase 3 randomised controlled trial of the Dutch colorectal cancer group. Lancet 385: 1843-1852, 2015.

11. Strosberg JR, Fine RL, Choi J, Nasir A, Coppola D, Chen DT, Helm J and Kvols L: First-line chemotherapy with capecitabine and temozolomide in patients with metastatic pancreatic endocrine carcinomas. Cancer 117: 268-275, 2011.

12. Ikenishi M, Ueda M, Kuroda A, Tsukazaki H, Nakao M, Takeuchi M, Konishi Y, Matsuda T, Figoni W, Ohtori T, et al: A study on drug interaction between warfarin and capecitabine with special reference to the co-administered term or the discontinuation term of capecitabine. Gan To Kagaku Ryoho 42: 833-839, 2015. 
13. Chu MP, Hecht JR, Slamon D, Wainberg ZA, Bang YJ, Hoff PM, Sobrero A, Qin S, Afenjar K, Houe V, et al: Association of proton pump inhibitors and capecitabine efficacy in advanced gastroesophageal cancer: Secondary analysis of the TRIO-013/LOGiC randomized clinical trial. JAMA Oncol 3 : 767-773, 2017.

14. Baan J, Bos MMEM, Gonesh-Kisoensingh SU, Meynaar IA, Alsma J, Meijer E and GVulto A: Capecitabine-induced toxicity: An outcome study into drug safety. J Integr Oncol 3: 113, 2014.

15. Cassidy J, Clarke S, Díaz-Rubio E, Scheithauer W, Figer A, Wong R, Koski S, Lichinitser M, Yang TS, Rivera F, et al: Randomized phase III study of capecitabine plus oxaliplatin compared with fluorouracil/folinic acid plus oxaliplatin as first-line therapy for metastatic colorectal cancer. J Clin Oncol 26: 2006-2012, 2008.

16. Hofheinz RD, Wenz F, Post S, Matzdorff A, Laechelt S, Hartmann JT, Müller L, Link H, Moehler M, Kettner E, et al: Chemoradiotherapy with capecitabine versus fluorouracil for locally advanced rectal cancer: A randomised, multicentre, non-inferiority, phase 3 trial. Lancet Oncol 13: 579-588, 2012.

17. Mayer RJ, Van Cutsem E, Falcone A, Yoshino T, Garcia-Carbonero R, Mizunuma N, Yamazaki K, Shimada Y, Tabernero J, Komatsu Y, et al: Randomized trial of TAS-102 for refractory metastatic colorectal cancer. N Engl J Med 372: $1909-1919,2015$

18. New drug extends lives of brain cancer patients. FDA Consum 39: 3, 2005.

19. Kunz PL, Catalano PJ, Nimeiri H, Fisher GA, Longacre TA Suarez CJ, Yao JC, Kulke MH, Hendifar AE, Shanks JC, et al: A randomized study of temozolomide or temozolomide and capecitabine in patients with advanced pancreatic neuroendocrine tumors: A trial of the ECOG-ACRIN Cancer Research Group (E2211). J Clin Oncol 36 (15 Suppl): S4004, 2018.

20. Marx J: Cancer. Encouraging results for second-generation antiangiogenesis drugs. Science 308: 1248-1249, 2005.

21. Llovet JM, Ricci S, Mazzaferro V, Hilgard P, Gane E, Blanc JF de Oliveira AC, Santoro A, Raoul JL, Forner A, et al: Sorafenib in advanced hepatocellular carcinoma. N Engl J Med 359: 378-390, 2008

22. Kudo M, Finn RS, Qin S, Han KH, Ikeda K, Piscaglia F, Baron A, Park JW, Han G, Jassem J, et al: Lenvatinib versus sorafenib in first-line treatment of patients with unresectable hepatocellular carcinoma: A randomised phase 3 non-inferiority trial. Lancet 391: 1163-1173, 2018

23. Tada T, Kumada T, Hiraoka A, Michitaka K, Atsukawa M, Hirooka M, Tsuji K, Ishikawa T, Takaguchi K, Kariyama K, et al: Safety and efficacy of lenvatinib in elderly patients with unresectable hepatocellular carcinoma: A multicenter analysis with propensity score matching. Hepatol Res 50: 75-83, 2020.

24. Ettrich TJ and Seufferlein T: Regorafenib. Recent Results Cancer Res 211: 45-56, 2018.

25. Grothey A, Van Cutsem E, Sobrero A, Siena S, Falcone A, Ychou M, Humblet Y, Bouché O, Mineur L, Barone C, et al: Regorafenib monotherapy for previously treated metastatic colorectal cancer (CORRECT): An international, multicentre, randomised, placebo-controlled, phase 3 trial. Lancet 381 : 303-312, 2013 .

26. Bekaii-Saab TS, Ou FS, Ahn DH, Boland PM, Ciombor KK, Heying EN, Dockter TJ, Jacobs NL, Pasche BC, Cleary JM, et al: Regorafenib dose-optimisation in patients with refractory metastatic colorectal cancer (ReDOS): A randomised, multicentre, open-label, phase 2 study. Lancet Oncol 20: 1070-1082, 2019.

27. Bruix J, Qin S, Merle P, Granito A, Huang YH, Bodoky G Pracht M, Yokosuka O, Rosmorduc O, Breder V, et al: Regorafenib for patients with hepatocellular carcinoma who progressed on sorafenib treatment (RESORCE): A randomised, double-blind, placebo-controlled, phase 3 trial. Lancet 389: 56-66, 2017.

28. Demetri GD, Reichardt P, Kang YK, Blay JY, Rutkowski P, Gelderblom H, Hohenberger P, Leahy M, von Mehren M, Joensuu $\mathrm{H}$, et al: Efficacy and safety of regorafenib for advanced gastrointestinal stromal tumours after failure of imatinib and sunitinib (GRID): An international, multicentre, randomised, placebo-controlled, phase 3 trial. Lancet 381: 295-302, 2013.

29. Grüllich C: Cabozantinib: A MET, RET, and VEGFR2 tyrosine kinase inhibitor. Recent Results Cancer Res 201: 207-214, 2014.

30. Abou-Alfa GK, Meyer T, Cheng AL, El-Khoueiry AB, Rimassa L, Ryoo BY, Cicin I, Merle P, Chen Y, Park JW, et al: Cabozantinib in patients with advanced and progressing hepatocellular carcinoma. N Engl J Med 379: 54-63, 2018.
31. Blumenthal GM, Cortazar P, Zhang JJ, Tang S, Sridhara R, Murgo A, Justice R and Pazdur R: FDA approval summary: Sunitinib for the treatment of progressive well-differentiated locally advanced or metastatic pancreatic neuroendocrine tumors. Oncologist 17: 1108-1113, 2012.

32. Raymond E, Dahan L, Raoul JL, Bang YJ, Borbath I, Lombard-Bohas C, Valle J, Metrakos P, Smith D, Vinik A, et al: Sunitinib malate for the treatment of pancreatic neuroendocrine tumors. N Engl J Med 364: 501-513, 2011.

33. George S, Blay JY, Casali PG, Le Cesne A, Stephenson P, Deprimo SE, Harmon CS, Law CN, Morgan JA, Ray-Coquard I, et al: Clinical evaluation of continuous daily dosing of sunitinib malate in patients with advanced gastrointestinal stromal tumour after imatinib failure. Eur J Cancer 45: 1959-1968, 2009.

34. Choi BS: Risks associated with sunitinib use and monitoring to improve patient outcomes. Korean J Intern Med 29: 23-26, 2014.

35. Pavel ME, Hainsworth JD, Baudin E, Peeters M, Hörsch D, Winkler RE, Klimovsky J, Lebwohl D, Jehl V, Wolin EM, et al: Everolimus plus octreotide long-acting repeatable for the treatment of advanced neuroendocrine tumours associated with carcinoid syndrome (RADIANT-2): A randomised, placebo-controlled, phase 3 study. Lancet 378: 2005-2012, 2011.

36. Yao JC, Fazio N, Singh S, Buzzoni R, Carnaghi C, Wolin E, Tomasek J, Raderer M, Lahner H, Voi M, et al: Everolimus for the treatment of advanced, non-functional neuroendocrine tumours of the lung or gastrointestinal tract (RADIANT-4): A randomised, placebo-controlled, phase 3 study. Lancet 387: 968-977, 2016.

37. Yao JC, Shah MH, Ito T, Bohas CL, Wolin EM, Van Cutsem E, Hobday TJ, Okusaka T, Capdevila J, de Vries EG, et al: Everolimus for advanced pancreatic neuroendocrine tumors. N Engl J Med 364: 514-523, 2011.

38. Lombard-Bohas C, Cariou B, Vergès B, Coriat R, N'guyen T, François E, Hammel P, Niccoli P and Hentic O: Management of metabolic disorders induced by everolimus in patients with differentiated neuroendocrine tumors: Expert proposals. Bull Cancer 101: 175-183, 2014 (In French).

39. Klümpen HJ, Beijnen JH, Gurney H and Schellens JH: Inhibitors of mTOR. Oncologist 15: 1262-1269, 2010.

40. Mesa RA: Imatinib and tyrosine kinase inhibition, in the management of BCR-ABL negative myeloproliferative disorders. Biologics 1: 129-138, 2007.

41. Dematteo RP, Ballman KV, Antonescu CR, Maki RG, Pisters PW, Demetri GD, Blackstein ME, Blanke CD, von Mehren M, Brennan MF, et al: Adjuvant imatinib mesylate after resection of localised, primary gastrointestinal stromal tumour: A randomised, double-blind, placebo-controlled trial. Lancet 373: 1097-1104, 2009.

42. Corless CL, Ballman KV, Antonescu CR, Kolesnikova V, Maki RG, Pisters PW, Blackstein ME, Blanke CD, Demetri GD, Heinrich MC, et al: Pathologic and molecular features correlate with long-term outcome after adjuvant therapy of resected primary GI stromal tumor: The ACOSOG Z9001 trial. J Clin Oncol 32: 1563-1570, 2014.

43. Joensuu H, Eriksson M, Sundby Hall K, Hartmann JT, Pink D, Schütte J, Ramadori G, Hohenberger P, Duyster J, Al-Batran SE, et al: One vs three years of adjuvant imatinib for operable gastrointestinal stromal tumor: A randomized trial. JAMA 307: 1265-1272, 2012

44. ESMO/European Sarcoma Network Working Group: Gastrointestinal stromal tumours: ESMO clinical practice guidelines for diagnosis, treatment and follow-up. Ann Oncol 25 (Suppl 3): iii21-iii26, 2014.

45. Blanke CD, Rankin C, Demetri GD, Ryan CW, von Mehren M, Benjamin RS, Raymond AK, Bramwell VH, Baker LH, Maki RG, et al: Phase III randomized, intergroup trial assessing imatinib mesylate at two dose levels in patients with unresectable or metastatic gastrointestinal stromal tumors expressing the kit receptor tyrosine kinase: S0033. J Clin Oncol 26: 626-632, 2008 .

46. Zalcberg JR, Verweij J, Casali PG, Le Cesne A, Reichardt P, Blay JY, Schlemmer M, Van Glabbeke M, Brown M and Judson IR; EORTC Soft Tissue and Bone Sarcoma Group, the Italian Sarcoma Group; Australasian Gastrointestinal Trials Group: Outcome of patients with advanced gastro-intestinal stromal tumours crossing over to a daily imatinib dose of $800 \mathrm{mg}$ after progression on 400 mg. Eur J Cancer 41: 1751-1757, 2005. 
47. Riese C, Weiß B, Borges U Jr, Beylich A, Dengler R Hermes-Moll K, Welslau M and Baumann W: Effectiveness of a standardized patient education program on therapy-related side effects and unplanned therapy interruptions in oral cancer therapy: A cluster-randomized controlled trial. Support Care Cancer 25: 3475-3483, 2017.

48. Favier-Archinard C, Leguelinel-Blache G, Cousin C, Gillet C, Bourquard P, Dubois F, Passemard N, Tora S, Rey A, Heraut B, et al: Élaboration d'un guide standardisé d'informations d'optimisation de l'adhésion médicamenteuse à dispenser lors d'une consultation pharmaceutique au patient atteint de myélome multiple: Validation finale. Bull Cancer 105: 1157-1172, 2018.

49. Moriwaki T, Fukuoka S, Taniguchi H, Takashima A, Kumekawa Y, Kajiwara T, Yamazaki K, Esaki T, Makiyama C, Denda T, et al: Propensity score analysis of regorafenib versus trifluridine/tipiracil in patients with metastatic colorectal cancer refractory to standard chemotherapy (REGOTAS): A Japanese society for cancer of the colon and rectum multicenter observational study. Oncologist 23: 7-15, 2018.
50. Patel AK, Barghout V, Yenikomshian MA, Germain G, Jacques P, Laliberté F and Duh MS: Real-world adherence in patients with metastatic colorectal cancer treated with trifluridine plus tipiracil or regorafenib. Oncologist 25: e75-e84, 2020.

51. Roila F, Molassiotis A, Herrstedt J, Aapro M, Gralla RJ, Bruera E, Clark-Snow RA, Dupuis LL, Einhorn LH, Feyer P, et al: 2016 MASCC and ESMO guideline update for the prevention of chemotherapy- and radiotherapy-induced nausea and vomiting and of nausea and vomiting in advanced cancer patients. Ann Oncol 27 (Suppl 5): v119-v33, 2016.

52. Gebbia V, Carreca I, Testa A, Valenza R, Curto G, Cannata G, Borsellino N, Latteri MA, Cipolla C, Florena M, et al: Subcutaneous octreotide versus oral loperamide in the treatment of diarrhea following chemotherapy. Anticancer Drugs 4: 443-445, 1993.

53. Bryce J and Boers-Doets CB: Non-rash dermatologic adverse events related to targeted therapies. Semin Oncol Nurs 30: 155-168, 2014.

54. Lalla RV, Sonis ST and Peterson DE: Management of oral mucositis in patients who have cancer. Dent Clin North Am 52: 61-77, viii, 2008. 